\title{
The Role of Monoamine System in Core Affects and Basic Emotions
}

\author{
Fushun Wang ${ }^{1,2,3 *}$ and Yiyuan Tang ${ }^{4}$ \\ ${ }^{1}$ Department of Neurosurgery, University of Rochester Medical Center, USA \\ ${ }^{2}$ Institute of Emotion, School of Psychology, Nanjing University of Chinese Medicine, China \\ ${ }^{3}$ Department of Surgery, Baylor Scott \& White Health, USA \\ ${ }^{4}$ Department of Psychological Sciences, Texas Tech University, USA
}

*Corresponding author: Fushun Wang, Department of Psychology, Institute of Emotion, Nanjing, University of Chinese Medicine, China.

Received Date: March 21, 2019

Published Date: April 01, 2019

\begin{abstract}
Affective disorders are a leading cause of disability worldwide, and drugs targeting monoamine neuromodulators are considered to be the first choice of treatment for these diseases. Here, we further explore the relationship between the monoamine neuromodulators with the core affects or basic emotions and try to give a very simple model for basic emotions: three primary color model. In this model, we try to put the 3 monoamines together with the core affects or basic emotions in a plane, like the threeprimary color: DA-reward (joy), NE- stress (fear and anger), and serotonin- punishment (sad). This model can be helpful to better understand the dynamics of basic emotions, the etiology of affective disorders such as depression, and the actions of respective psychoactive drugs.
\end{abstract}

Keywords: Basic emotions; Monoamine; Core affect; Dopamine; Norepinephrine; Serotonin; Stress; Reward; Punishment

\section{Introduction}

Affective disorders, such as depression, have been identified as a leading cause of disability worldwide [1]. However, the treatments are not as good as expected, because of lacking knowledge about neural basis for emotions. Studies of the neural basis of emotion have a long history within neuroscience and are still an active field of experimental and theoretical research [2]. Most of the work focuses on identifying neural structures responsible for emotions. This work culminated in the invention of limbic system theory of emotion around mid-19th century. However, this work was frustrated by fMRI studies which want to find a specific locus for a specific basic emotion [3-5].

Anyway, there is one thing that has been proved to be right is the monoamine basis for emotions. Monoamine (including serotonin, noradrenaline and dopamine) has been showed to be the substrate for emotion ever since the 50s-60s in last century [6]. So far, most the antidepressant and anti-psychotic drugs are targeting the monoamine system, and dysfunctions of the monoamine system have been proved to be involved in many mental disorders such as depression [1,7-9], anxiety [10], post-traumatic disorders [11], and attention-deficit hyperactivity disorder [12-14]. The monoamine producing systems originate from three most concentrated neuclei (locus coeruleus- norepinephrine; raphe nucleus- serotonin, ventral tegmental area-dopamine), and project their axons and release these neuromodulators diffusely and widely throughout the cerebral cortex [15]. These properties fit perfectly with one property of emotion: "all or none" properties for an emotion. This means if you are happy, the whole brain will be happy; if you are angry, the whole brain will be angry. So, it might be nonsense trying to find one specific locus in the brain for one basic emotion.

However, even though many studies from differentresearch field support the idea that monoamines are the substrate for emotions [16], their effects are still quite mixed. For example, antidepressant drugs affect almost all the monoamine neuromodulators and are also used for almost all affective diseases such as anxiety, phobia, depression et. al [17]. There is a need to improve the 
conceptualization and classification of the emotional states and the monoamine neuromodulators. Here we review some experimental papers about their difference in modulating emotions and try to differentiate their functions in controlling emotion and behavior. In addition, we will introduce a new hypothesis about monoamine with core affects: three monoamine neuromodulators underlie the 3 core affects (dopamine-reward, serotonin-punishment, norepinephrine-stress), and they work together to make different basic emotions, like the three primary colors. The dopamine system has been proved to be involved in reward [18-20], the noradrenaline has been related to the "fight or flight" responses at stressful events [21,22], and the serotonin system seems to be related to punishment [23].

\section{The Monoamine System and Core Affects}

\section{Norepinephrine-stress}

The brain norepinephrine system is well known to be activated by acute stress $[1,24,25]$. The stress is any threat, either real or perceived, to the organism, which would induce robust NE release. Following exposure to a stressor, norepinephrine is released from the LC to almost all the brain cortex and other limbic areas, such as hypothalamus, which was prompted to release corticotropin releasing hormone to activate the HPA axis (hypothalamuspituary-adrenaline axis) [24,26-28], where more norepinephrine/ epinephrine is released from the sympathetic system to the blood. Even though the LC is very small, the axons of these neurons project to essentially the whole brain, and potentially influence the entire nervous system $[29,30]$. The robust norepinephrine release will lead the animal to certain kind of active behavior: "fight or flight" $[24,31,32]$. In the periphery autonomous nervous system, NE acts as a sympathetic neurotransmitter, together with adrenaline, acts as stress hormones, directly increases heart rate, triggers the release of glucose, and increases blood flow to skeletal muscles, to be ready for "fight-or-flight" responses [8,19,33-39], or "fear and anger emotions $[24,37,40,41]$.

\section{Dopamine - reward}

Ever since Wise (1980) proposed the hedonic hypothesis of dopamine, mesolimbic dopamine in the brain has long been linked to the rewarding processes in almost all the animal kingdom [4246] and proposed that dopamine is a signal of stimulus salience, providing feeling of enjoyment. From then on, lots of papers have confirmed dopamine's role in the rewarding signals [47-53]. For example, many studies on intracranial self-stimulation have established the important role of the dopamine system in reward behavior [51,54-56]. In addition, drug addictions have been proved to be involved in the reward system by affecting dopamine release, reuptake inhibition [20,45,57-60]. Together, these studies suggest an involvement of dopamine neurotransmission in the acute and long-term rewarding system [58,61-63].

\section{Serotonin - punishment}

Serotonin plays a critical role in a wealth of psychiatric conditions, such as depression, manic anxiety and obsessive compulsions [64-66]. However, despite the importance of serotonergic pharmacotherapies, its roles in normal emotion are still mysterious [66]. Its major function can be divided into three aspects: 1) serotonin is involved in prediction of aversive events $[23,67]$; 2) it is involved in behavioral inhibition, preventing ongoing action in light of prediction of aversive outcomes [68]; 3) it is involved in the treatment of depression [66]. These functions are rather complicated and seem contradict to each other $[69,70]$. More than 20 years ago, Deakin and Graeff hypothesized that some serotonin pathways are involved in response to aversive stimuli $[23,66]$, and dysfunction of these pathways contributes to the pathophysiology of anxiety and affective disorders [69,71]. And later many more studies have related serotonin to punishment, for example, Robinson shows that "serotonin is critical for punishmentinduced inhibition" [72] and Dayan concluded that: "At a global level, serotonin is richly involved in the behavioral neuroscience of punishment and threat" [66,70].

\section{Monoamine and Basic Emotions}

The stress, reward and punishment are the core features of emotions, or core affects. Core affects are not emotions by themselves [73], instead they are just three characteristics of emotions. These three core characterizations constitute four basic emotions: fear and anger, joy, sadness (Figure 1) [16,34,74]. The three core affects are also related to three kinds of behaviors: stress"fight or flight", reward- "relax and enjoy", punishment- "freeze and inhibition" [1] (Figure 1).

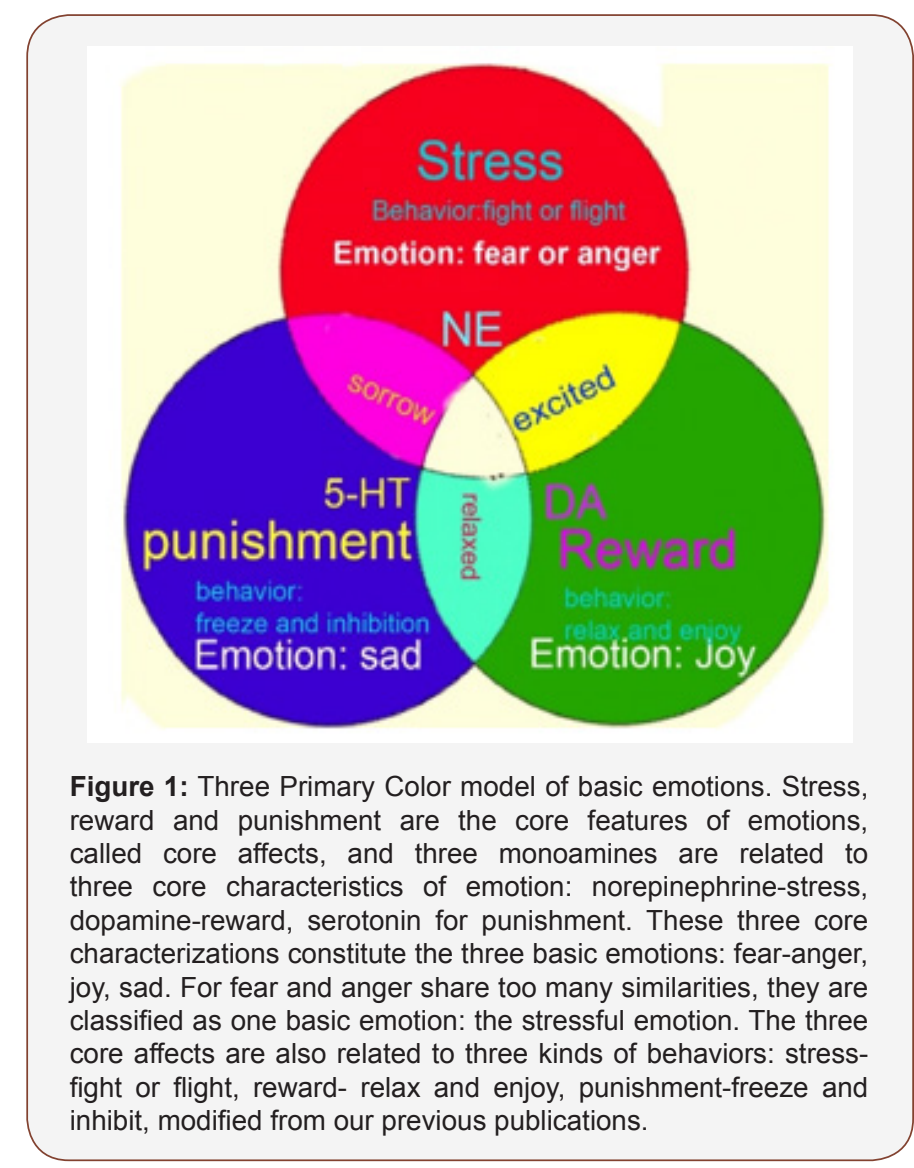

Stress results from threat to the homeostasis and wellbeing of the human being8, and it is due to uncertainty about the situation 
[8]. Stress can activate the NE/LC system, which induces "fight or flight" behaviors, and "fear and anger" emotions [75]. It seems that stress first induce fear due to the first appraisal, then anger with the secondary appraisal [76]. Fear is associated with appraisals of uncertainty and induce avoidance; while anger is associated with certainty and induce approaching [37]. According to Lazarus's reappraisal theory, after the second appraisal, an individual employs a positive reappraisal (happy, or rewarding emotions will be induced) and negative reappraisal (sad, or punishing emotions will be induced) [77,78]. The emotion joy is due to positive reappraisal: coping successfully, this is really the case for dopamine neurons $[61,79,80]$, dopamine can be released by successfully removing the stress, or coping successfully with the stressful situation $[79,81]$. Therefore, dopamine release is not determined by rewarding stimuli or aversive stimuli, it is determined by if the coping process is successful or not $[55,79]$. We might also extend this process to the emotion joy or happy: the happy emotion is due to successfully coping with the situation, which can induce relaxation and enjoyment.

At stressful event or traumatic event, people might experience negative reappraisal [82], which is due to coping failure. Therefore, emotion sadness is due to negative reappraisal: coping failure. Like dopamine's role in reward prediction error, and the role of aversion prediction error was also proposed for serotonin [83]. Therefore, serotonin is due to coping failure, and we might also extend this definition to the emotion sad. Serotonin is correlate positively with aversion and negatively with reward [66]. Serotonin has a major behavioral effect is suppression or inhibition or freezing, or the behavior resulted from sad emotion is relaxation and enjoyment. This is a kind of passive avoidance by not doing actions at punishment, which is different from active avoidance of fight and flight induced by norepinephrine [84].

\section{Conclusion}

This paper presents a new model for monoamine neuromodulators and basic emotions, like primary colors: red-NEstress-fear/anger, green-reward-joy, blue-punishment-sadness. Many papers have linked the monoamine neuromodulators to basic emotions, such as the "new three-dimension model" [15], which arranged the basic emotions in a three-dimensional equation. Here, we further explore the relationship between the monoamine neuromodulators with the basic emotions and get an even simpler model: three primary color model. In this model, we try to put the 3 monoamine neuromodulators in a plane: dopamine-joygreen, norepinephrine-surprise-red and serotonin-dislike-blue (Figure 1). This model is very simple, and it will be very helpful to better understand the dynamics of basic emotions, the etiology of affective disorders such as depression, and the actions of respective psychoactive drugs.

\section{Acknowledgment}

This work was supported by a grant from Foundation of Humanities and Social Science in Ministry of Education in China (Fushun Wang, 19YJAZH083).

\section{Competing Financial Interest}

The authors declare no competing financial interests.

\section{Funding}

NIH: R61AT010138.

\section{References}

1. Gu S, Wang W, Wang F, Huang JH (2016) Neuromodulator and Emotion Biomarker for Stress Induced Mental Disorders. Neural Plast 2016: 2609128.

2. LeDoux J (1996) The emotional brain. In: Simon and Schuster.

3. Lindquist KA, Siegel EH, Quigley KS, Barrett LF (2011) The hundred-year emotion war: are emotions natural kinds or psychological constructions? Comment on Lench, Flores, and Bench. Psychol Bull 139(1): 255-263.

4. Lindquist K, Barrett L (2012) A functional architecture of the human brain: emerging insights from the science of emotion. Trends Cogn Sci 16: 533-540.

5. Hutto DD, Robertson I, Kirchhoff MD (2018) A New, Better BET: Rescuing and Revising Basic Emotion Theory. Front Psychol 9: 1217.

6. Schildkraut JJ, Kety SS (1967) Biogenic amines and emotion. Science 156(3771): 21-37.

7. Gu S, Jing L, Li Y, Huang JH, Wang F (2018) Stress Induced Hormone and Neuromodulator Changes in Menopausal Depressive Rats. Front Psychiatry 9: 253.

8. Zheng Z, Simeng Gu, Yu Lei, Shanshan Lu, Wei Wang, et al. (2016) Safety Needs Mediate Stressful Events Induced Mental Disorders. Neural Plast 2016: 8058093 .

9. Tye KM, Julie J Mirzabekov, Melissa R Warden, Emily A Ferenczi, HsingChen Tsai, et al. (2013) Dopamine neurons modulate neural encoding and expression of depression-related behaviour. Nature 493: 537-541.

10. Robinson OJ, Overstreet C, Allen PS, Pine DS, Grillon C (2012) Acute tryptophan depletion increases translational indices of anxiety but not fear: serotonergic modulation of the bed nucleus of the stria terminalis? Neuropsychopharmacology 37: 1963-1971.

11. Geracioti TD, Baker DG, Ekhator NN, West SA, Hill KK, et al. (2001) CSF norepinephrine concentrations in posttraumatic stress disorder. Am J Psychiatry 158: 1227-1230.

12. Dougherty DD, Bonab AA, Spencer TJ, Rauch SL, Madras BK, et al. (1999) Dopamine transporter density in patients with attention deficit hyperactivity disorder. Lancet 354: 2132-2133.

13. Biederman J, Faraone SV (2005) Attention-deficit hyperactivity disorder Lancet 366: 237-248.

14. Del Campo N, Chamberlain SR, Sahakian BJ, Robbins TW (2011) The roles of dopamine and noradrenaline in the pathophysiology and treatment of attention-deficit/hyperactivity disorder. Biol Psychiatry 69(12): e145-157.

15. Lovheim $\mathrm{H}$ (2012) A new three-dimensional model for emotions and monoamine neurotransmitters. Med Hypotheses 78(2): 341-348.

16. Wang F, Pereira A (2016) Neuromodulation, Emotional Feelings and Affective Disorders. Mens Sana Monogr 14: 5-29.

17. Liang BF, Huang F, Wang HT, Wang GH, Yuan X, et al. (2015) Involvement of norepinephrine and serotonin system in antidepressant-like effects of hederagenin in the rat model of unpredictable chronic mild stressinduced depression. Pharm Biol 53: 368-377.

18. Haber SN, Knutson B (2010) The reward circuit: linking primate anatomy and human imaging. Neuropsychopharmacology 35: 4-26.

19. Bressan RA, Crippa JA (2005) The role of dopamine in reward and pleasure behaviour--review of data from preclinical research. Acta Psychiatr Scand Suppl: 14-21.

20. Diana M (2011) The dopamine hypothesis of drug addiction and its potential therapeutic value. Front Psychiatry 2: 64 
21. Benarroch EE (2009) The locus ceruleus norepinephrine system: functional organization and potential clinical significance. Neurology 73: $1699-1704$.

22. Herrmann N, Lanctot KL, Eryavec G, Khan LR (2004) Noradrenergic activity is associated with response to pindolol in aggressive Alzheimer's disease patients. J Psychopharmacol 18(2): 215-220.

23. Tops M, Russo S, Boksem MA, Tucker DM (2009) Serotonin: modulator of a drive to withdraw. Brain Cogn 71(3): 427-436.

24. Morilak DA et al. (2005) Role of brain norepinephrine in the behavioral response to stress. Prog Neuropsychopharmacol Biol Psychiatry 29(8): $1214-1224$

25. Gu S, Wang F, Yuan T, Guo B, Huang H (2015) Differentiation of primary emotions through neuromodulators: review of literature. International journal of neurology research 1: 43-50.

26. Leonard BE (2001) Stress, norepinephrine and depression. J Psychiatry Neurosci 26 Suppl: S11-16.

27. Birnbaum S, Gobeske KT, Auerbach J, Taylor JR, Arnsten AF (1999) A role for norepinephrine in stress-induced cognitive deficits: alpha-1adrenoceptor mediation in the prefrontal cortex. Biol Psychiatry 46 $1266-1274$

28. Barbieri A, Bimonte S, Palma G, Luciano A, Rea D, et al. (2015) The stress hormone norepinephrine increases migration of prostate cancer cells in vitro and in vivo. Int J Oncol 47: 527-534.

29. Bott-Flugel L, Bernshausen A, Schneider H, Luppa P, Zimmermann K, et al. (2011) Selective attenuation of norepinephrine release and stressinduced heart rate increase by partial adenosine A1 agonism. PLoS One 6(3): e18048

30. Ma S, Morilak DA (2005) Norepinephrine release in medial amygdala facilitates activation of the hypothalamic-pituitary-adrenal axis in response to acute immobilisation stress. J Neuroendocrinol 17: 22-28.

31. Bernuci MP, Leite CM, Barros P, Kalil B, Leoni GB, et al. (2013) Transitory activation of the central and ovarian norepinephrine systems during cold stress-induced polycystic ovary in rats. J Neuroendocrinol 25(1): 23-33.

32. Bennun A (2010) Characterization of the norepinephrine-activation of adenylate cyclase suggests a role in memory affirmation pathways. Overexposure to epinephrine inactivates adenylate cyclase, a causal pathway for stress-pathologies. Biosystems 100: 87-93.

33. Chrousos GP (2009) Stress and disorders of the stress system. Nat Rev Endocrinol 5: 374-381.

34. Wang F, Pan F, Lee LA, Huang JH (2017) Stress induced neuroplasticity and mental disorders. Neural plasticity 2017: 1-3.

35. WangF, Pan F, Shapiro LA, Huang JH (2018) Stress Induced Neuroplasticity and Mental Disorders 2018. Neural Plast 2018: 5382537.

36. Boyanova L (2017) Stress hormone epinephrine (adrenaline) and norepinephrine (noradrenaline) effects on the anaerobic bacteria Anaerobe 44:13-19.

37. Moons WG, Eisenberger NI, Taylor SE (2010) Anger and fear responses to stress have different biological profiles. Brain Behav Immun 24: 215219.

38. Pereira TD, Murthy M (2017) To Fight or Not to Fight. Neuron 95: 986988.

39. Kringelbach ML (2005) The human orbitofrontal cortex: linking reward to hedonic experience. Nat Rev Neurosci 6(9): 691-702.

40. Leonard BE (2002) Stress, norepinephrine and depression. Acta Neuropsychiatr 14: 173-180

41. Koob GF (1999) Corticotropin-releasing factor, norepinephrine, and stress. Biol Psychiatry 46: 1167-1180.

42. Zhang K, Guo JZ, Peng Y, Xi W, Guo A (2007) Dopamine-mushroom body circuit regulates saliency-based decision-making in Drosophila. Science 316: 1901-1904
43. Bozarth MA, Wise RA (1980) Electrolytic microinfusion transducer system: an alternative method of intracranial drug application. Journal of neuroscience methods 2(3): 273-275.

44. Bozarth MA, Gerber GJ, Wise RA (1980) Intracranial self-stimulation as a technique to study the reward properties of drugs of abuse. Pharmacol Biochem Behav 13 Suppl 1: 245-247.

45. Volkow ND, Wang GJ, Fischman MW, Foltin RW, Fowler JS, et al. (1997) Relationship between subjective effects of cocaine and dopamine transporter occupancy. Nature 386: 827-830.

46. Rohwedder A, Wenz NL, Stehle B, Huser A, Yamagata N, et al. (2016) Four Individually Identified Paired Dopamine Neurons Signal Reward in Larval Drosophila. Curr Biol 26: 661-669.

47. Liu, C, Plaçais PY, Yamagata N, Pfeiffer BD, Aso Y, let al. (2012) A subset of dopamine neurons signals reward for odour memory in Drosophila. Nature 488: 512-516.

48. Bergamini G, Sigrist H, Ferger B, Singewald N, Seifritz E, et al. (2016) Depletion of nucleus accumbens dopamine leads to impaired reward and aversion processing in mice: Relevance to motivation pathologies. Neuropharmacology 109: 306-319.

49. Muhammed K, Sanjay Manohar, Michael Ben Yehuda, Trevor TJ Chong, George Tofaris, et al. (2016) Reward sensitivity deficits modulated by dopamine are associated with apathy in Parkinson's disease. Brain 139: 2706-2721.

50. Schultz W (2016) Dopamine reward prediction-error signalling: a twocomponent response. Nat Rev Neurosci 17: 183-195.

51. Sharp ME, Foerde K, Daw ND, Shohamy D (2016) Dopamine selectively remediates 'model-based' reward learning: a computational approach. Brain 139: 355-364

52. Saddoris MP, Sugam JA, Carelli RM (2017) Prior Cocaine Experience Impairs Normal Phasic Dopamine Signals of Reward Value in Accumbens Shell. Neuropsychopharmacology 42: 766-773.

53. Frank S, Veit R, Sauer H, Enck P, Friederich HC, et al. (2016) Dopamine Depletion Reduces Food-Related Reward Activity Independent of BMI. Neuropsychopharmacology 41: 1551-1559.

54. Mora F, Ferrer JM (1986) Neurotransmitters, pathways and circuits as the neural substrates of self-stimulation of the prefrontal cortex: facts and speculations. Behav Brain Res 22(2): 127-140.

55. Rada PV, Mark GP, Hoebel BG (1998) Dopamine release in the nucleus accumbens by hypothalamic stimulation-escape behavior. Brain Res 782: $228-234$

56. Stauffer WR, Lak A, Kobayashi S, Schultz W (2016) Components and characteristics of the dopamine reward utility signal. J Comp Neurol 524: 1699-1711.

57. Haydon PG, Blendy J, Moss SJ, Rob Jackson F (2009) Astrocytic control of synaptic transmission and plasticity: a target for drugs of abuse? Neuropharmacology 56 Suppl 1: 83-90.

58. Willuhn I, Wanat MJ, Clark JJ, Phillips PE (2010) Dopamine signaling in the nucleus accumbens of animals self-administering drugs of abuse. Curr Top Behav Neurosci 3: 29-71.

59. Galaj E, Harding W, Ranaldi R (2016) Dopamine D1 and D3 receptor interactions in cocaine reward and seeking in rats. Psychopharmacology (Berl) 233: 3881-3890.

60. Volkow ND, Wang GJ, Fowler JS, Logan J, Gatley SJ, et al. (1997) Decreased striatal dopaminergic responsiveness in detoxified cocaine-dependent subjects. Nature 386: 830-833.

61. Eshel N, Tian J, Bukwich M, Uchida N (2016) Dopamine neurons share common response function for reward prediction error. Nature neuroscience 19: 479-486.

62. Hadar R, Voget M, Vengeliene V, Haumesser JK, van Riesen C, et al. (2017) Altered neural oscillations and elevated dopamine levels in the reward pathway during alcohol relapse. Behav Brain Res 316: 131-135.

63. Udupa K, Chen R (2016) Deeper understanding of the role of dopamine in reward, learning, and motivation. Mov Disord 31: 498. 
64. Petty F, Kramer G, Moeller M (1994) Does learned helplessness induction by haloperidol involve serotonin mediation? Pharmacol Biochem Behav 48: 671-676.

65. Petty F, Kramer G, Wilson L, Jordan S (1994) In vivo serotonin release and learned helplessness. Psychiatry Res 52: 285-293.

66. Dayan P, Huys JM (2008) Serotonin, inhibition and negative mood. Plos computational biology 4: e4.

67. Helmbold, K, Zvyagintsev M, Dahmen B, Bubenzer-Busch S, Gaber TJ, et al. (2015) Effects of serotonin depletion on punishment processing in the orbitofrontal and anterior cingulate cortices of healthy women. Eur Neuropsychopharmacol 25(6): 846-856.

68. Fonseca MS, Murakami M, Mainen ZF (2015) Activation of dorsal raphe serotonergic neurons promotes waiting but is not reinforcing. Curr Biol 25: 306-315.

69. Deakin JF, Graeff FG (1991) 5-HT and mechanisms of defense. Psychopharmacol 5(4): 305-315.

70. Dayan P, Huys Q J (2009) Serotonin in affective control. Annu Rev Neurosci 32: 95-126.

71. Deakin JF (1983) Roles of brain serotonergic neurons in escape, avoidance and other behaviors. J Psychopharmacol 43: 563-577.

72. Robinson OJ, Cools R, Sahakian BJ (2012) Tryptophan depletion disinhibits punishment but not reward prediction: implications for resilience. Psychopharmacology (Berl) 219: 599-605.

73. Izard CE (2009) Emotion theory and research: highlights, unanswered questions, and emerging issues. Annu Rev Psychol 60: 1-25.
74. Gu, S, Mengdan Gao, Yaoyao Yan, Fushun Wang, Yi-yuan Tang, et al. (2018) The Neural Mechanism Underlying Cognitive and Emotional Processes in Creativity. Front Psychol 9: 1924.

75. lazarus RS, Folkman S (1984) Stress, appraisal, and coping

76. Folkman S, Lazarus RS, Dunkel-Schetter C, DeLongis A, Gruen RJ (1986) Dynamics of a stressful encounter: cognitive appraisal, coping, and encounter outcomes. J Pers Soc Psychol 50: 992-1003.

77. Lazarus RS (1999) Stress and emotion: a new synthesis.

78. Aldwin CM (1994) Stress, coping, and development.

79. Cabib S, Puglisi-Allegra S (1994) Opposite responses of mesolimbic dopamine system to controllable and uncontrollable aversive experiences. J Neurosci 14: 3333-3340.

80. Schultz W, Dayan P, Montague PR (1997) A neural substrate of prediction and reward. Science 275: 1593-1599.

81. Spreux-Varoquaux O, Alvarez JC, Berlin I, Batista G, Despierre PG, et al. (2001) Differential abnormalities in plasma 5-HIAA and platelet serotonin concentrations in violent suicide attempters: relationships with impulsivity and depression. Life Sci 69: 647-657.

82. Chaouloff F, Berton O, Mormede P (1999) Serotonin and stress. Neuropsychopharmacology 21: 28S-32S.

83. Amat J, Baratta MV, Paul E, Bland ST, Watkins LR, et al. (2005) Medial prefrontal cortex determines how stressor controllability affects behavior and dorsal raphe nucleus. Nature neuroscience 8(3): 365-371.

84. Dayan P (2012) Twenty-five lesson from computational neuromodulation. Neuron 76: 240-256 